FACTA UNIVERSITATIS

Series: Mechanical Engineering Vol. 18, No 4, 2020, pp. 545 - 564

10.22190/FUME200510021S

Original scientific paper

\title{
OPTIMAL FEED RATE CONTROL STRATEGIES FOR FRICTION DRILLING
}

\section{Roman Stryczek, Paweł Blaszczak}

Faculty of Mechanical Engineering and Computer Science, University of Bielsko-Biala, Poland

\begin{abstract}
The presented paper contains the results of research aimed at developing optimal strategies for controlling the feed rate in the friction drilling process. In particular, the use of linear variable feed rate for individual drilling stages and adaptive feed rate control have been tested. The experiments were carried out with the use of a CNC machine tool equipped with an axial force and torque sensor. Correlation between thrust force and torque was shown, respectively, in relation to the feed drive load and the drive of machine tool spindle. Based on this, a feed rate sensorless control strategy was created to protect against excessive and long-term overload both of the tool and the drives. The following assessment criteria were considered: drilling cycle time, maximum values of thrust and torque, maximum values of feed drive load and drive of machine tool spindle, maximum power and energy effect in the form of work necessary to perform during the drilling process and forming the hole flange. The obtained test results, made for low-carbon steel with a tungsten carbide tool, indicate the advantage of the approach based on the linear variable feed rate and adaptive control over the traditional drilling process based on the step change of the feed rate, according to the recommendations given by the tool manufacturers.
\end{abstract}

Key words: Friction Drilling, Feed Rate, Optimization, Adaptive Control

\section{INTRODUCTION}

One of the noticeable trends in modern machine and device constructions is the increasing use of thin-walled components. This results in material saving and a less weight of the designed structures. However, there is a problem of assembling this type of elements with other parts of the product, the solution would be to make drilling holes using the friction drilling technique. Friction drilling is an alternative method of holemaking process using heat in sheet metal, pipes and thin-walled profiles made of low-

Received May 10, 2020 / Accepted July 05, 2020

Corresponding author: Roman Stryczek

Faculty of Mechanical Engineering and Computer Science, University of Bielsko-Biala, Willowa 2, 43-300, Bielsko-Biała, Poland

E-mail: rstryczek@ath.bielsko.pl 
melting point metallic materials. During the friction drilling process, as a result of friction between the drill and the workpiece, there is a rapid increase in temperature, which causes plastic deformation of the workpiece in the area of operation of the drill. The material. displaced in this way forms a bushing, significantly extending the length of the hole and, consequently, also the active length of the formed thread. All material removed from the hole contributes to the formation of the bushing. The properties of the material and its microstructure change during friction drilling due to high temperature and strain. The use of friction drilling as hole-making technique implies an improvement of surface integrity [1]. Friction drilling presents a deformed zone which does not appear during conventional drilling. This deformed zone provides an appropriate geometry for next productions steps such as threading or joining processes. In [2, 3], the authors showed that the friction threads lead to much better mechanical, profile and microstructural property. The thread has a significantly larger number of turns, hence the screw connection ensures high strength. Stronger threads are produced, also thanks to iso-stress level lines which are parallel to the thread profile. Bushing can also be used as a supporting hole for welded and soldered joints. The relatively recently widespread friction drilling technique is quickly gaining new applications, especially in automotive industry, aviation industry, in the production of lighting devices, medical devices, furniture industry, ventilation devices, fitness, etc. Its main advantages are: increasing the active length of a hole, improving the strength of the thread connection, wasteless production, productivity, long tool life, up to over 10000 cycles, possibility to apply to many different construction materials, simple tooling and a clean workplace.

Numerous publications on friction drilling focus on attempts to create a process model, most often based on the finite element method (FEM), to enable better understanding of the complex physical-chemical phenomena associated with this process: material flow, temperature distribution, stress and strain. Chow et al. [4] studied the relationship between drill surface temperature, tool wear and axial thrust force in friction drilling AISI 304 stainless steel by tungsten carbide drills with and without coating. Li at al. [5] developed an improved theoretical model of the drilling force in friction drilling, which took into account changes in temperature, pressure and friction coefficient. It can be the basis for optimization of tool design. El-Bahloul et al. [6, 7] studied combinations of thermal drilling parameters such as tool diameter, tool friction angle, friction contact area ratio (FCAR), thickness of the workpiece, feed rate and rotational speed and their effect on thrust, torque, hole diameter error, error roundness and bushing length. To evaluate the results, fuzzy logic elements were used. The paper [8] presents a series of experiments that has been carried out to determine the impact of selected parameters on the quality of the bushing obtained as a result of friction drilling. Su et al. [9] showed that the ratio between material thickness and drill diameter has a decisive impact on the busing quality. Bustillo et al. [10] proposed a suitable smart manufacturing strategy to the friction-drilling process joining materials with very different mechanical and chemical properties. Pereira et al. [1] analyzed the feasibility of friction drilling technique from a technical and environmental point of view. The absence of cutting fluids in machining processes is a key aspect which implies a drastic reduction of environmental footprint. Friction drilling is the solution to the problem of joining thin-walled structural elements in a simple, economical, ecological and very effective way.

In general, the research confirms the high complexity of the process, resulting from the numerous and diverse set of input parameters which influence the output parameters (Fig. 
1). Therefore, all previously generated models of friction drilling process are fragmentary in nature, they are mainly limited to three input variables and one to three output parameters. The range of variability of input parameters is very narrow and does not always take into account technically achievable and the most economically justified values. The test stands used, as in [6, 7], for example, have significant technical limitations that make it impossible to test a broader range of process parameters. Furthermore, the research most often concerned the operation of new drills, without analysis of the impact of drill wear on the process and output parameters of the drilling cycle. Due to the long life of the tool in the friction drilling process, the impact of drill wear on the hole quality can only be tested under the conditions of industrial production.



Fig. 1 Input and output parameters of the friction drilling process

Experimental research and the development of theoretical models also enable research on parametric optimization of this process. Pantawane and Ahuja [12] using the statistical analysis method the Response Surface Method (RSM) optimized the drill rotational speed, the feed rate and the tool diameter, due to the hole diameter error, and roughness of the inner surface of the formed bushing. The research demonstrated a noticeable increase in variability of diameter dimensions with an increase in feed rate. In the paper [12], the length of the busing obtained during friction drilling was maximized depending on the rotational speed, thickness of galvanized steel sheet and angle of the conical section of the drill. The established artificial neural network technique model is effectively integrated with simulated annealing algorithm approach to give optimum processing conditions in thermal drilling. Jiang et al. [13] used the Gray Relational Analysis to determine the impact of friction angle, FCAR, feed rate, and drilling speed on the surface roughness and the bushing length. Similar research was performed by $\mathrm{Ku}$ et al. [14] who stated that surface roughness is mainly influenced by feed rate and rotational speed of the tool, while only FCAR has a significant impact on the length of the bushing. In the paper [15] it was found that the surface roughness of the drilled hole was the dominant output characteristic in the thermal drilling process. On the basis of the 
research, it was found that spindle speed and tool angle have a greater impact on the surface roughness of the galvanized steel sheet than the impact of the workpiece thickness. This paper also presents a set of different methods for optimization of friction drilling process. Patil and Bembrekar [16] analyzed the impact of rotational speed and feed rate on thermal stress, hardness and the bushing length for aluminum and mild steel.

At the same time, there is a lack of research on parametric optimization of friction drilling process, in terms of cycle time, tool life, load on machine tool drives and energy expenditure. The potential user is interested in performance and economic aspects of the manufacturing process. Therefore, he would be interested in quick selection of machining conditions that guarantee short cycle times and at the same time economic tool life, use of the machine tool production potential, process automation and control of its correct course. Manufacturers of friction drills inform the user about the recommended machining parameters, at the same time indicating that these are good starting parameters and require verification along with growing user's experience.

So far, in mass production, the friction drilling process has been carried out on specialized devices. In order to extend the scope of application of this technique and at the same time automate the drilling cycle, it would be necessary to adapt universal numerically controlled machine tools (NC), equipping them with simple, programmed process controllers. For NC machine tools, there are no standard machining cycles dedicated to friction drilling yet.

The analysis of the scientific publications clearly indicates existence of a research gap in the field of optimization of the friction drilling process from the point of view of user-relevant aspects such as process efficiency, its energy consumption, utilization of the CNC machine tool potential both in terms of the available main drive and feed drive power as well as control functions. In addition to the economic benefits, such approach to optimization generates also ecological progress in the form of reduced energy consumption and less environmental pollution, as the friction drilling process is a clean and waste-free process. The premises determined above have induced the authors of this paper to develop an intelligent, sensorless strategy for control of the friction drilling process. The term intelligence is understood here as the ability to adapt to change.

The presented paper describes a new model for control of the friction drilling process, taking into account the intelligent functions adapting the feed rate to the currently performed stage of drilling, the capabilities of the machine tool drives and the condition of the tool. For this purpose, it has been necessary to:

- perform a new breakdown of the friction drilling process into stages, the floating limits of which set the maximum load values for the machine tool drives; the proposals for the breakdown of this process into stages known from the literature take into account only the geometrical aspects, which are not useful in the context of adaptive control of the feed rate;

- identify the correlations between the thrust and torque and the load of the machine tool drives;

- develop an advanced form of the numerical filter in order to limit the impact of the input signal disturbance on the quality of control of the feed rate;

- develop an algorithm being capable of correcting of the programmed value of feed rate correction in real time, adjusting it to the capabilities of the machine tool and of the tool, taking into account all restrictions related to the proper course of the process. 


\section{TEST STAND}

Test stand (Fig. 2) was based on a TUG-56 lathe equipped with a $7 \mathrm{~kW}$ spindle drive motor and $1.26 \mathrm{~kW}$ each feed drive motors. The machine tool is equipped with the SINUMERIK 810D numerical control system, with an additional external digital input/output panel enabling the control of synchronous actions. The tool is integrated into the machine tool spindle using the ER25 collet chuck. The workpiece was square tubing with wall thickness of $2 \mathrm{~mm}$, made of carbon steel S235JRH EN 10219. The object was mounted in a tool holder integrated with a dynamometer. Each time, before the next drilling cycle, it was again determined to ensure the centricity of the drill axis and the dynamometer axis. Piezoelectric dynamometer Kistler model 9272A, together with the controller and software for the acquisition, visualization and archiving of measured values, was used to measure axial force and torque during the friction drilling process. Other force components occurring between the tool and the workpiece do not have a significant impact on the analysis of this process. The equipment is supplemented with the SIMATIC FIELD PG programmer for real-time recording of: drive loads, programmed feed rate, relative axial position of the tool tip (indications of Z-axis of machine tool) and calculation parameters used in the adaptive control algorithm. The latest versions of the CNC controller software already have a built-in tracking and visualization function of the machine tool operating parameters, therefore additional recording devices are unnecessary in such cases.

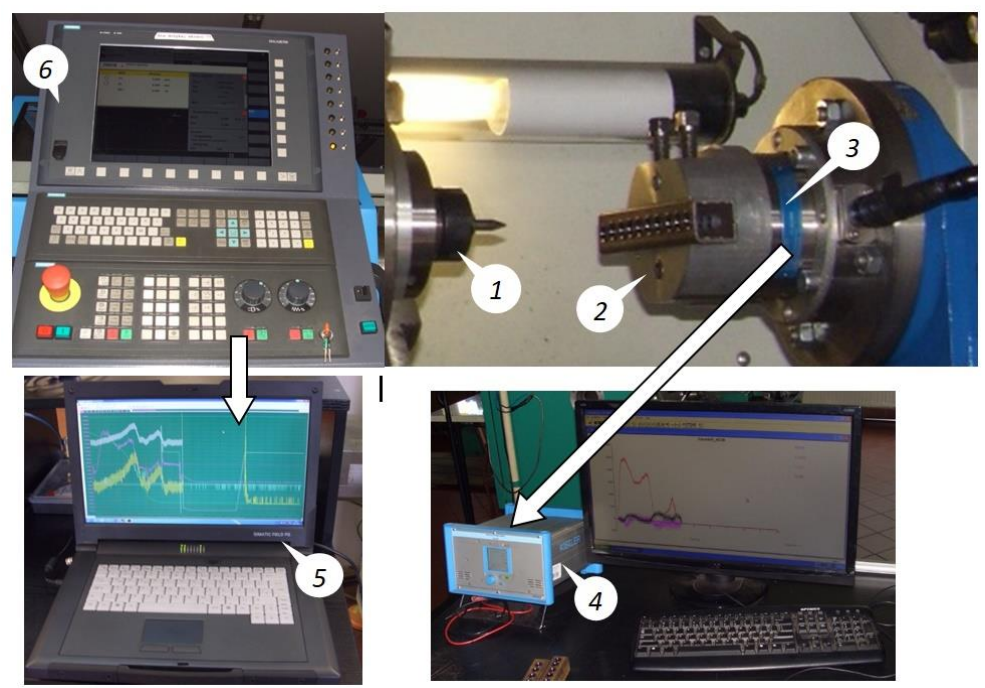

Fig. 2 Experimental setup: fixture for the tool (1), fixture for the workpiece (2), dynamometer (3), controller (4), programmer (5), CNC control panel (6)

A typical friction drilling tool can be divided into five parts: shank, collar, calibration part, conical part and center (Fig. 3). In new drill designs, the conical and cylindrical parts have a modified shape (A-A cross-section) to limit the contact area between the tool and the material. Fig. 3 shows the key dimensions of the tungsten carbide drill used in the tests. 


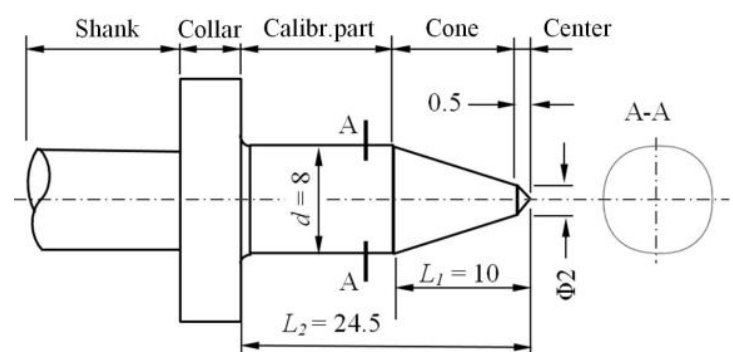

Fig. 3 Regions and key dimensions of the friction drilling tool

In numerous publications, the authors divide the friction drilling process into stages on the basis of geometric quantities determined by the mutual positions of the tool and the workpiece. In the presented publication, the boundaries of stages are determined on the basis of observation of the tool load. Fig. 4 shows the stages of the friction drilling cycle. The recorded courses of thrust force and torque occurring in the process of friction drilling are typical and coincide with the recorded courses included in numerous works, regardless of whether they concern soft alloys [17] or difficult-to-machine materials [18]. The limits of the basic stages A and B determine the maximum thrust (axial force) and the maximum torque value, respectively.

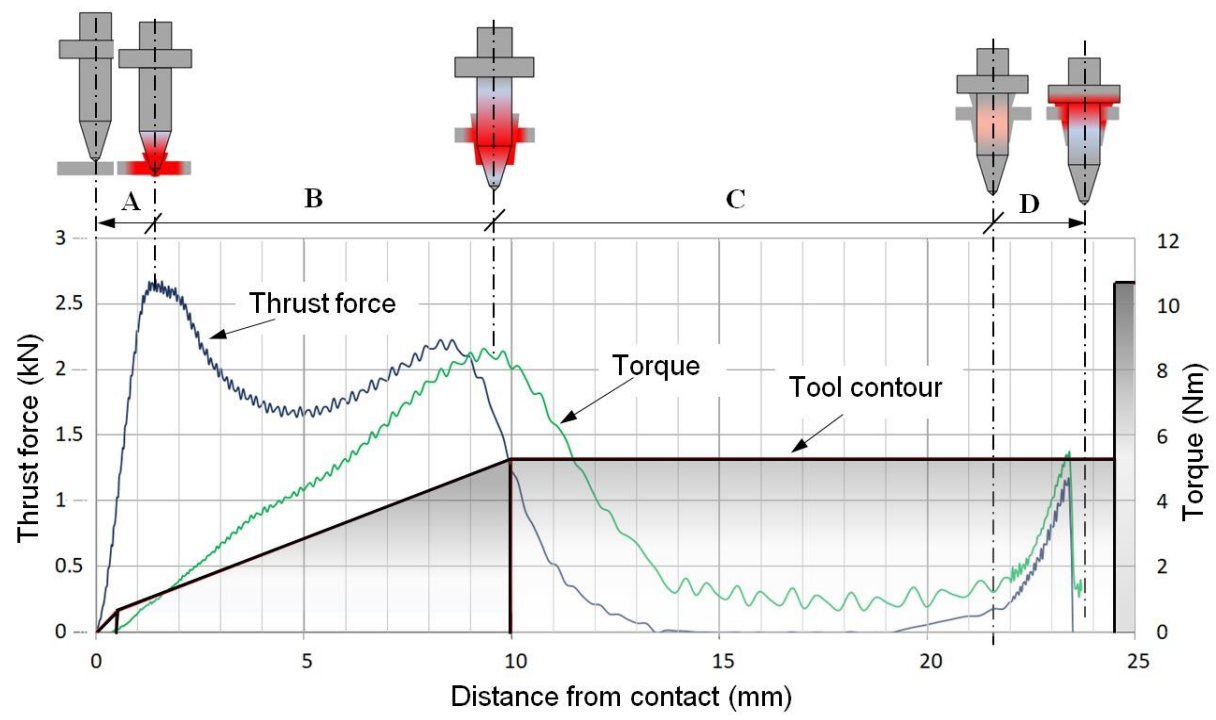

Fig. 4 Stages displaced in this way forms a bushing, significantly extending the length of the hole and, of friction drilling

\section{ANALYSIS OF THRUST FORCE AND TORQUE IN THE FRICTION DRILLING CYCLE}

During the first stage of the process (A), the material is locally heated to a high temperature, depending on the type of material and process parameters, i.e. tool rotation 
speed and axial feed rate. Mechanical energy of friction is converted into heat, a deformation of the thermoplastic material occurs, as a result of which an initial, irregular flash is formed. At this stage, a rapid increase in thrust is noticeable, which reaches its maximum value even before the perforation of the hole. When the tool almost penetrates the material, high stress is generated inside the hole due to material compression. Torque values gradually increase, but do not reach high values in this phase, which is mainly due to the small diameter of the contact area between the tool and the material. Excessive increase in feed rate at this stage results in smaller ductility of the material because there is less time to generate enough heat for plastic deformation. The high thrust causes adhesive and frictional wear of the drill on the conical section, which causes the formation of round grooves on this section of the tool $[20,21]$. These grooves also cause greater adhesion of the material to the tool during subsequent drilling cycles, which adversely affects the quality of the worked surface, also reducing tool life. This may cause greater variability in the diameter dimension of the drilled hole [22]. Therefore, at this stage, the axial feed rate recommended by the manufacturer should not be significantly exceeded.

At the beginning of stage $\mathrm{B}$, high temperature causes decrease of thrust force. The hole is perforated and its inner cylindrical part is formed. As the tool moves deeper into the material, the active tool radius increases, which increases the torque until it reaches its maximum value. Increased resistance is caused by friction force at the end of the tapered surface of the drill and deformations of the formed bushing. At stage B, there are significant differences in thrust and torque in subsequent drilling cycles, which indicates that the process is highly unstable at this stage.

Stage $\mathrm{C}$ is a sterile transition of the tool for shaping the external flash and occurs only in cases where the length of the drill is excessive. Standard drills are produced in two versions: short and long. Rarely the length of the drill is perfectly matched to the size of the bushing produced. During stage $\mathrm{C}$, there is a sharp decrease in both torque and thrust. The implementation of stage $\mathrm{C}$ with the same feed rate as stages $\mathrm{A}$ and $\mathrm{B}$ is then irrational. Moreover, we should bear in mind that the external flash formed at stage A quickly lowers the temperature, which is undesirable if it is further formed by the drill flange.

Stage D consists in shaping and smoothing the upper burr by compressing the flash formed at stage A. There are two options when it comes to this upper burr; one possibility is that it is crushed between the tool ring and the piece, which implies that process is absolutely chipless. The other possibility is that the material is removed from the workpiece by a chip breaker located around the tool shank. During stage D, both axial force and torque increase. In case of difficult-to-machine materials such as: AISI304, Ti$6 \mathrm{Al}-4 \mathrm{~V}$ or Inconel718 and a low feed rate of tool at stage C, thrust and torque at this stage can reach maximum values, which was confirmed in [18]. In case of soft materials and acceleration of feed rate at stage $\mathrm{C}$, thrust and torque do not reach high levels, which was also demonstrated in this paper. Too high values of tool load during this stage mean the necessity to verify the trajectory and parameters of tool feed. At the end of stage D, the axial force and torque decrease to zero, which is associated with deceleration of feed drive. In other publications authors also consider tool retraction phase. This stage is usually carried out with a fast movement, so it has not been considered in this study because it had no effect on the results tested. 
The above analysis shows that both the axial feed rate and the rotational speed of the tool have a significant impact on the level of thrust and torque. Friction drilling process requires higher speeds than conventional drilling methods. The required rotational speed of the tool is conditional on the hole diameter, material thickness and type of material. Increase in rotational speed causes an increase in temperature, which results in greater ductility of the material, and thus a decrease in thrust and torque, and this entails better working conditions for the tool. We should bear in mind, however, that an increase above the recommended temperature value of the tool $750^{\circ} \mathrm{C}$ [19], $900^{\circ} \mathrm{C}$ [23], in turn, causes a rapid decrease in the life of the drill. Therefore, it is advisable to use rotational speed recommended by the tool manufacturer. Therefore, the user has to choose the axial feed rate as a parameter determining the time of the drilling cycle and the load on the main drive and feed drive.

If the machining process is carried out with a worn out tool the friction between the tool and the workpiece increases, and energy consumption increases as well [24]. If the worn out tool is not replaced in due time, it can increase production costs, it can cause downtime or even a machine failure. Energy consumption monitoring during subsequent friction drilling cycles may prevent the above-mentioned negative cases.

Fig. 5 presents a comparison between axial force and torque indications during a cycle for a new and worn out drill after 10000 operating cycles.

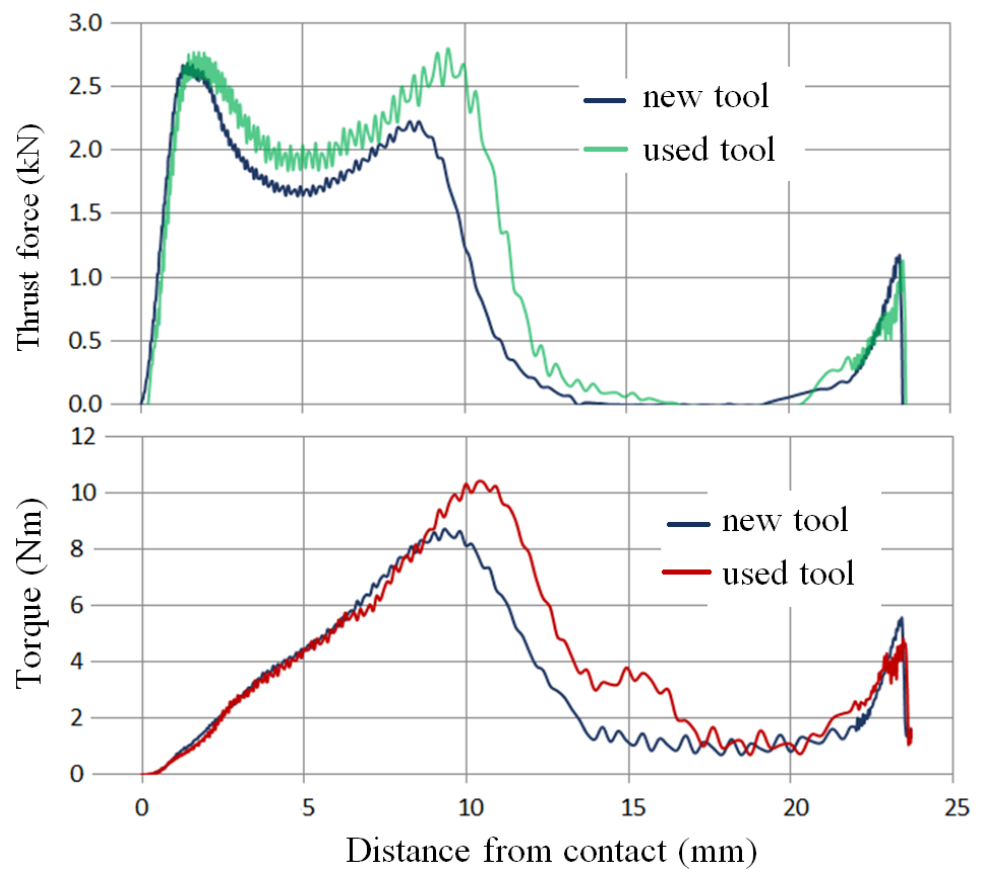

Fig. 5 Comparison of thrust and torque for a new and worn out friction drill

Machining parameters, i.e. spindle rotation and feed rate during the experiment were kept constant and identical in both tests. Significant changes that can be observed are 
mainly due to the tool surface wear in the area located between the conical and cylindrical part of the tool. It results in shifting the maximum main drive load by about $2 \mathrm{~mm}$, which should be included in the process parameters. The boundaries of areas A and B as well as the maximum values of axial force and torque change with the progressive wear of the drill. Hence, the optimal tool feed rate should change in adaptive mode adapting to the current condition of the drill. The process parameters recommended by the tool manufacturer are suitable for the new, unused tool. In order to ensure proper operating parameters for the entire tool life, a flexible, automated procedure should be developed for changing its operating parameters with the progressive tool wear.

\section{Strategies for Controlling Feed Rate in the Friction Drilling Process}

In a significant part of experimental research, a constant feed rate was adopted for all stages of drilling, which seems irrational from the point of view of the above-said analysis. Manufacturers of friction drilling tools provide their customers with recommended feed rates which are constant in subsequent drilling phases. This has obvious benefits, but is still not the optimal solution. Therefore, the authors have developed a new method - which has not been presented in the technical and scientific literature yet - of a linear feed rate change in the individual stages of the drilling cycle, additionally modified with an adaptive strategy for adjustment of the feed rated to the possibility of the assumed load of the machine tool drives, taking into account the restrictions resulting from ensuring of the proper plasticization of the material.

The selection of the optimal feed rate is a complex issue and should be considered on a case-by-case basis. In the paper [7], special attention has been paid to the importance of thermal conductivity of the material in this respect. For example, the low thermal conductivity of Ti-6Al-4V causes a low rate of heat transfer, the workpiece slowly becomes soft and then also it slowly loses heat. Long period of time needed to generate sufficient heat and to ensure proper softening of the material causes rapid wear of the drilling tool. On the other hand, it also takes a long time to lower the temperature of the molten material. Low thermal conductivity, which causes poor heat transfer in the whole material, is the main cause of severe plastic deformation with surface delamination on the inner periphery of the bushing.

Fig. 6 shows the recorded thrust force and torque values for three friction drilling cycles that differ in terms of feed rate. The simplest $F_{\text {Const }}$ strategy assumes a constant feed rate over the entire drilling process. The strategy, according to the recommendations of the manufacturer of $F_{S e c}$ tool provides for a stepped change in the feed rate at individual sections of the drilling process. The $F_{\text {Lin }}$ strategy is based on a linear change of the feed rate in the area of individual process phases, avoiding its abrupt changes. The values of thrust (Fig. 7) and torque (Fig. 8) in case of $F_{S e c}$ and $F_{\text {Lin }}$ strategies are at a similar level, while the cycle time (Fig. 9) for the $F_{\text {Lin }}$ strategy is about $30 \%$ shorter than the cycle time for the $F_{\text {Sec }}$ strategy. In case of the simplest $F_{\text {Const }}$ strategy the cycle time is definitely extended, therefore, it should not be taken into account in industrial applications for mass production. 


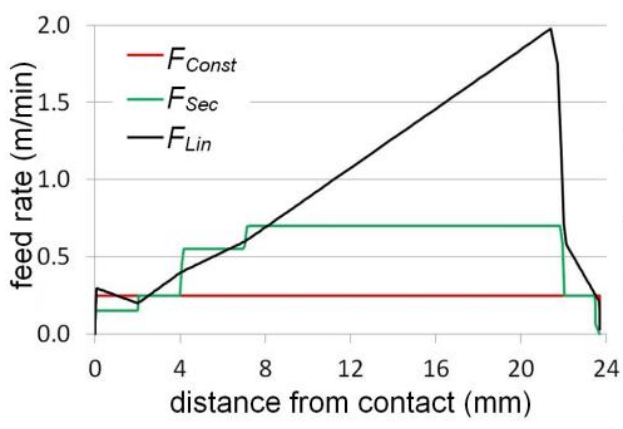

Fig. 6 Feed rate for drilling strategies

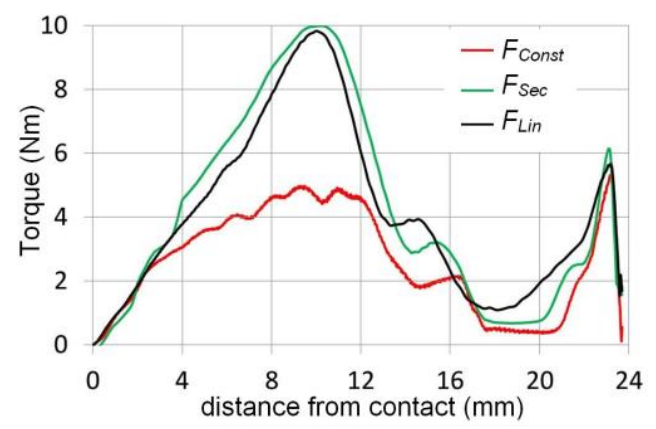

Fig. 8 Torque for drilling strategies

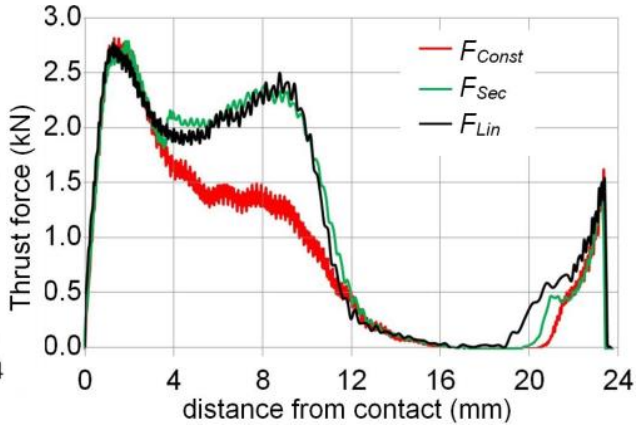

Fig. 7 Thrust for drilling strategies

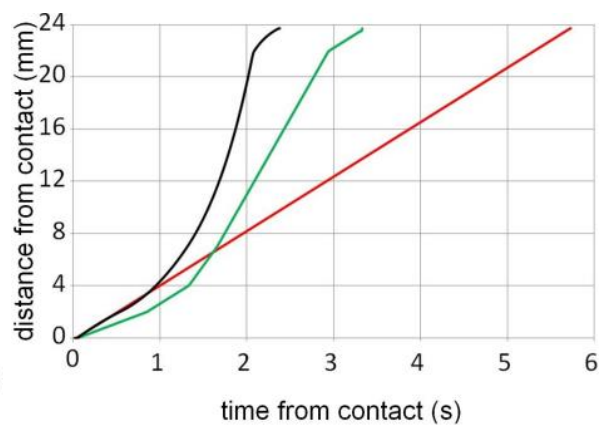

Fig. 9 Cycle time for drilling strategies

As illustrated by the example, linearly varying feed rates at individual stages of the friction drilling cycle have many significant advantages. However, an unsolved problem remains of how to pre-set the feed rate and how to react to changes in stage boundaries as the tool working surfaces wear out? The solution to the above-said problem may be properly selected strategy of automatic feed rate correction, maximizing, wherever possible, its value and at the same time not allowing to exceed the permissible load on the tool and machine tool drives. Therefore, it is necessary to roughly determine the feed rates and limits of their variability and then to optimize their real values in the adaptive mode.

\subsection{Adaptive control of the friction drilling process}

Because it is very rare that friction drilling machine tools are equipped with a dynamometer to measure thrust and torque, the assumed strategy of adaptive feed rate control uses the load on the feed drives and the spindle as input data. The values of these loads are available in modern numerical control systems of CNC machine tools in the form of system variables, as a percentage of the maximum load of a given drive. This allows the use of such variables as input data in the adaptive control strategy. There is a strong correlation between the quantities measured with a dynamometer, i.e. thrust and torque, and the load on the feed rate, respectively (Fig. 10) and spindle drive (Fig. 11). 
The initial stroke of spindle drive load observed results from the spindle acceleration to nominal revolutions.

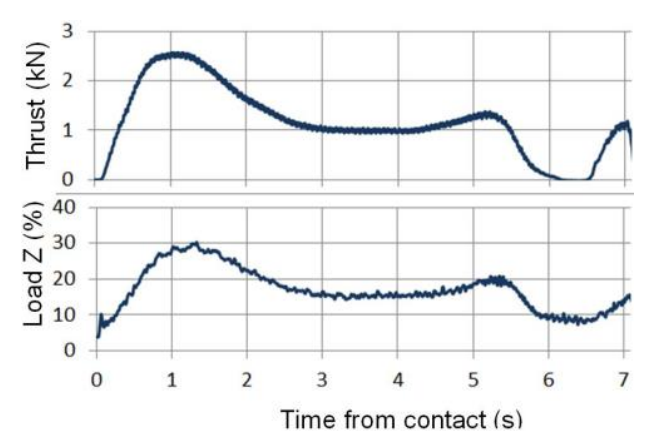

Fig. 10 Thrust and feed drive load



Fig. 11 Torque and spindle drive load

The proposed strategy for controlling the feed rate is schematically shown in Fig. 12. The actual, currently implemented working feed rate is influenced by the programmed value of linear variable feed rate and programmable, expressed as a percentage of feed rate correction $(O V R)$. An upper limit of $O V R$ has been set, reaching $200 \%$. We can assume that the feed rate actually applied can reach a value in the range of $\left(0,2 \cdot F_{p r}\right]$, where $F_{p r}$ is programmed feed rate value. The $O V R$ value in a given interpolator cycle $(I P O)$ depends on the current main drive load, feed drive load and $O V R$ value in the previous IPO.



Fig. 12 General scheme of adaptive control of the friction drilling process 
The basic input signals of the control algorithm, i.e. the feed drive load and the spindle drive load are subject to interference resulting from imperfections of their reading and inevitable process instability. Signal containing significant interference should therefore be filtered, otherwise the input signal oscillations would also cause oscillations of the $O V R$ output parameter. Furthermore, as $O V R$ is also an input signal such adverse oscillations would be amplified. During the research, an advanced filter containing a differential element was selected, allowing, to a large extent, to take into account the expected form of the signal in subsequent interpolator cycles. Attempts to apply a signal averaging resulted in a clear delay in response in case of dynamically changing loads. Due to a significant role of temperature, in case of friction drilling process there is a much greater dynamics of changes than during e.g. rolling process or conventional drilling. Therefore, a digital filter was applied in the form of three components: inertia, current reading and forecasted values. Their influence is determined respectively by the weights: $w_{i}, w_{a}$ and $w_{p}$. A simple filter form was obtained, which is easy to program in synchronous actions

$$
L_{f_{k}}^{d}=w_{i} L_{f_{k}}^{d}+w_{a} L_{k}^{d}+w_{p}\left(L_{f_{k-1}}^{d}+\left(L_{f_{k-1}}^{d}-L_{k-2}^{d}\right)\right),
$$

where: $L_{f k}$ - filtered drive load in $k$ - in $I P O, d \in\{\mathrm{C} \leftarrow$ spindle drive, $\mathrm{Z} \leftarrow$ feed drive $\}, \mathrm{w}_{\mathrm{a}}$ - weight of the current drive load, $\mathrm{w}_{\mathrm{i}}$ - weight of inertia block, $\mathrm{w}_{\mathrm{p}}$ - weight of predicted load value. Tests have shown correct functioning of the filter with the weight values respectively: $w_{i}=0.4, w_{a}=0.1, w_{p}=0.5$, as illustrated in Fig. 13 . The filter taking into account the predicted values generates a slight delay, about $0.03 \mathrm{~s}$, twice smaller than the standard filter, while sufficiently smoothing the signal. In the second step of the method, the $L_{R}$ relative drive load $d$ is calculated as the ratio of the current load value and the $L_{s e t}$ user's preferred load value as

$$
L_{R}^{d}=L_{f}^{f} / L_{s e t}^{d}
$$



Fig. 13 Feedback signal of the drive load

This allows us to compare the feed drive load and spindle drive, taking into account the preferences and experience of the machine tool user. For further calculations, only higher value of relative load of the spindle drive or feed drive shall be taken into account. 
Correction coefficient $C_{F}$ for the feed rate shall be determined. If the relative load value taken into account is higher than 1 , then the correction coefficient for the feed rate takes the value between $(-1,0]$. If the relative load is less than 1 , then the correction coefficient for the feed rate takes the values between $[0,1]$. These values are calculated based on the relationship (3). The $b$ factor allows you to control the intensity of the correction. Fuzzy functions (4) were used to determine the new OVR' value.

$$
\begin{gathered}
C_{F}^{d}=\left\{\begin{array}{cl}
1-\sqrt{\left.e^{-b \cdot\left[1-1\left(L_{R}^{d}+0.001\right)\right.}\right]^{2}} & \text { if } \rightarrow L_{R}^{d} \leq 1 \\
-1+\sqrt{e^{-b\left(1-L_{R}^{d}\right)^{2}}} & \text { if } \rightarrow L_{R}^{d}>1
\end{array}\right. \\
O V R^{\prime}=\left\{\begin{array}{cc}
\left(C_{F}^{d}+1\right) \cdot O V R & \text { if } \rightarrow L_{R}^{d}>1 \\
O V R_{\max } \cdot\left(\frac{O V R}{O V R_{\max }}+C_{F}^{d}-\frac{O V R \cdot C_{F}^{d}}{O V R_{\max }}\right) & \text { if } \rightarrow L_{R}^{d}<1
\end{array}\right.
\end{gathered}
$$

Fig. 14 illustrates the functioning of the applied strategy of adaptive feed speed control in friction drilling. The shaded areas indicate the areas affected by exceeding the assumed load values of the feed drives $(25 \%)$ and the spindle drive $(40 \%)$ on the shaping of the programmed correction of the feed rate and, consequently, the implemented feed rate. Exceeding the permissible $L_{\text {set }}$ values resulted in an increase above 1 of relative load value of the $L_{R}$ drive and a decrease below 0 of the value of the $C_{F}$ correction coefficient. Negative $F_{C}$ values result in a continuous decrease in the programmed value of $O V R$ feed rate correction, the intensity of the $O V R$ decrease depends on the amount of exceeding the permissible load values of the drives. After overloading the drives, the $O V R$ quickly returns to its maximum value of $200 \%$. The constant feed rate in the first two seconds of the cycle is due to the fact that the adaptive control is turned off during this time to provide time for a sufficient temperature rise and plasticization of the material. The constant feed rate at the first drilling stage is selected in accordance with the tool manufacturer's recommendations.

\subsection{Selection of nominal feed rate}

In accordance with the applied adaptive control strategy and based on the tests carried out (Fig. 14), the currently implemented feed rate shall be affected by the programmed feed rate in the $F_{P r}$ control program. Programmed feed corrector can compensate for the effects of dynamically changing drilling conditions only to some extent. When programming the feed rate in the initial stages of the friction drilling cycle, the user can follow the recommendations of the tool manufacturer and/or his own experience. The proposed adaptive strategy of controlling the feed rate together with the possibility of visualizing the formulation of drive loads and variables $O V R$ and $F$ in the full drilling cycle allows the user in a few steps also to optimally select the $F_{P r}$ feed rate. Below the results of three tests have been presented that allow the user to determine whether the programmed feed rates in the next program phases are satisfactory. Fig. 15 illustrates the first selected feed rate $F_{p r}$ and the response to such feed rate of the $O V R$ and $F$ variables. 




Fig. 14 Impact of load on the feed rate
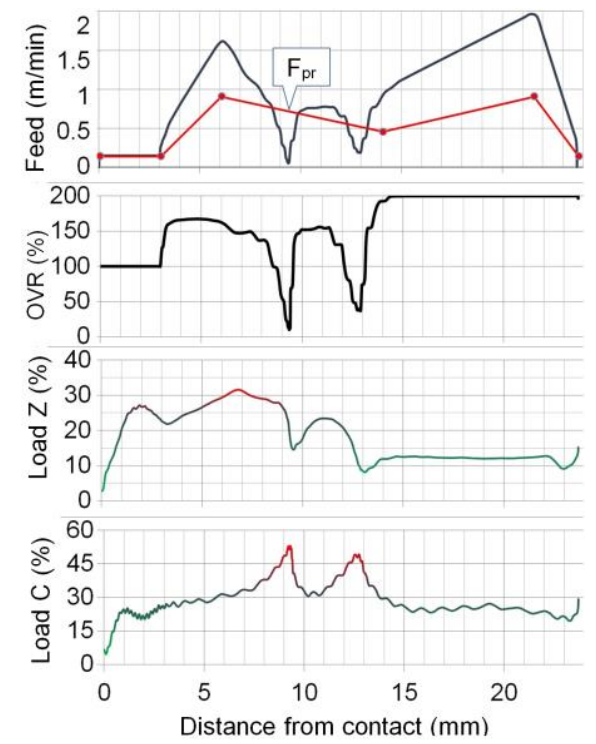

Fig. 15 Test for $\mathrm{L}_{\text {set }}^{\mathrm{Z}}=30 \%$ and $\mathrm{L}_{\text {set }}=40$

The analysis of the feed drive load during the first $3 \mathrm{~mm}$ of drilling clearly indicates that the assumed period of heating and plasticizing of the material is too long and can be limited. After $2 \mathrm{~mm}$ of drilling, the feed drive load is clearly reduced. Even earlier, after about $1 \mathrm{~mm}$, the rapid increase in load of spindle drive stops. Therefore, in the next test, it was decided that the first stage should be shortened to $2 \mathrm{~mm}$ with a slight increase in the feed rate during the last phase to $250 \mathrm{~mm} / \mathrm{min}$. The next observation indicates that at the drilling section between $6 \mathrm{~mm}$ and $13 \mathrm{~mm}$ the assumed feed drive load and spindle drive load were exceeded. At this section, the final part of the bushing is formed. Therefore, in the next test, a different, trapezoidal feed rate was suggested for this section (Fig. 16).

Lowering the feed in this section is also driven by the need to maintain acceptable quality of the hole. Excessive feed rate at this stage has a negative effect on the shape and active length of the hole, causing cracks and petal formation [2]. In case of exceeding 13 $\mathrm{mm}$ there was no risk of drive overloading, therefore the maximum feed rate $F_{P r}$ was set there. A slight modification by $0.5 \mathrm{~mm}$ was also proposed in the penultimate point of the $F_{P r}$ trajectory.

As Fig. 16 indicates, as a result of the actions taken, a number of positive effects were achieved: the tool load was smoothed, rapid changes in $O V R$ and $F$ controlled variables were removed, and apparent overloading of the recommended loads on the machine tool drives were avoided. The feed drive load at the critical section oscillates between $\pm 2 \%$ of the value selected by the user. Cycle time remained virtually unchanged. 


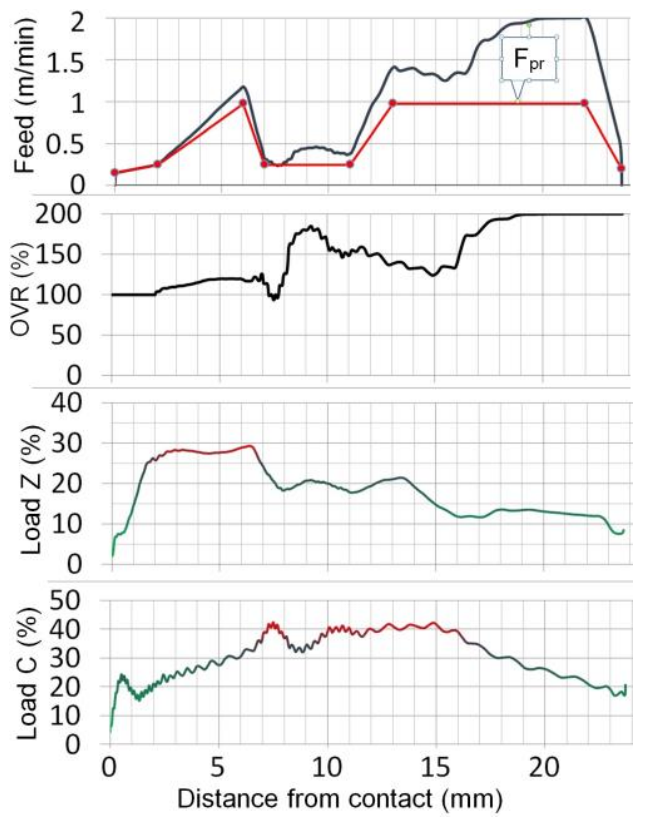

Fig. 16 Test $\mathrm{L}_{\text {set }}=30 \%$ and $\mathrm{L}^{\mathrm{C}}{ }_{\text {set }}=40 \%$


Fig. 17 Test for $\mathrm{L}_{\text {set }}=40 \%$ and $\mathrm{L}_{\text {set }}=50 \%$

Analysis of the input variable $F_{P r}$ and the output variable $F$ presents the remaining reserves and threats, and thus further optimization of the $F_{P r}$ variable. The most sensitive point of the $F_{P r}$ trajectory remains the point located $7 \mathrm{~mm}$ from the contact point between the tool and the material. Moving it to the left by $0.5 \mathrm{~mm}$ should remove the threat. However, extending the trajectory section for which $F_{P r}=1000 \mathrm{~mm} / \mathrm{min}$ applies by $1 \mathrm{~mm}$ to the left and to the right will not threaten the stability of the process. The control algorithm, however, compensates for this type of "inaccuracy" of the feed rate control trajectory, so it is not necessary to make the above changes. The last test presented concerns another problem: what will be the response of adaptive control to a significant increase in the permissible load of drives. $L_{S e t}$ values have been increased from $30 \%$ to $40 \%$ for feed drive and from $40 \%$ to $50 \%$ for spindle drive, with constant $F_{P r}$ values. The results are shown in Fig. 17. During the full cycle, the permissible load values for the drives were not exceeded, despite the fact that the $O V R$ variable reached values over $180 \%$. Loads have been smoothed as compared to the previous test, which should be considered as a positive phenomenon. The cycle time was shorter by $18 \%$. Therefore, this test indicates a different manner of searching for optimal $F_{P r}$ values. In case of the assumed limit values of drive loads, an $O V R$ similar to that presented in Fig. 17 should be obtained. 


\subsection{Influence of feed rate control strategy on energy consumption in the friction drilling cycle}

Power and energy analysis in friction drilling process provides basic information concerning machine requirements, such as spindle selection and chuck design. Energy consumption during the friction drilling cycle may also be one of the criteria determining the correctness of the adopted process parameters and tool wear. During machining process heat is generated and it is a negative factor in the process. Therefore, we try to ensure that most of the heat generated in the process is discharged through the chips and emulsion outside the machining zone. Friction drilling is a non-chip drilling method, and we don't use emulsion to cool the tool and workpiece. Most of the energy consumed in the friction drilling cycle is converted into heat and transferred to the workpiece and tool. The heat generated is necessary for material ductility, but excessive heat generation limits tool life. The compromise solution is to generate the necessary amount of heat without increasing the mechanical load on the tool and the tool load associated with thermal shock. The test stand is equipped with a dynamometer measuring forces and torque in the friction drilling process, it is possible to calculate the energy expenditure to make the hole and forming the bushing and the flange. The total energy expenditure of the process is of course greater, which results from energy losses associated with the efficiency of the drive and mechanical systems of machine tool.

The necessary energy in the friction drilling process is the sum of the $E_{Z}$ energy associated with thrust in the direction of the drilling axis and the $E_{C}$ energy associated with overcoming torque in the rotational movement of the tool [25]. Both thrust and the torque were measured by a dynamometer. The course of instantaneous energy values related to one $I P O$ cycle (0.01s) was determined according to the equations (5) and (6):

$$
\begin{gathered}
E_{Z}^{I P O}=F_{a} \cdot d Z^{I P O} \\
E_{C}^{I P O}=0.01 \cdot T_{a} \cdot 2 \pi S / 60
\end{gathered}
$$

where: $F_{a}$ - average thrust value in the IPO, $d Z^{I P O}$ - the distance covered in the IPO, $T_{a}$ average torque value in the $I P O, \mathrm{~S}$ - Spindle rotation. The total energy $E$ necessary to make the hole was expressed as follows:

$$
E=\int_{0}^{\Delta t}\left(E_{Z}^{I P O}+E_{C}^{I P O}\right) d t,
$$

where $\Delta t$ - the total drilling time.

The momentary values of energy resulting from thrust (8) and torque (19) are presented below for new and used drill. Thrust and torque for this test have been shown earlier in Fig. 5. Test results indicate a small share of thrust, less than $4 \%$ in the total energy needed to make the hole during friction drilling and flange forming. The total energy necessary to make the hole, excluding energy losses resulting from the efficiency of the drives and mechanical systems of machine tool, was $1992 \mathrm{~J}$ for a new drill and $2178 \mathrm{~J}$ for a used drill. The increase in energy consumption by nearly $10 \%$ indicates the possibility of tracking the degree of drill consumption based on the energy consumed in subsequent drilling cycles. 


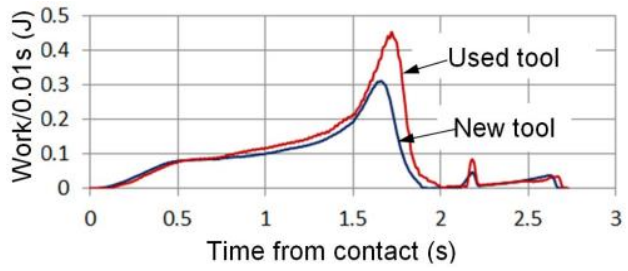

Fig. 18 Energy consumption from thrust

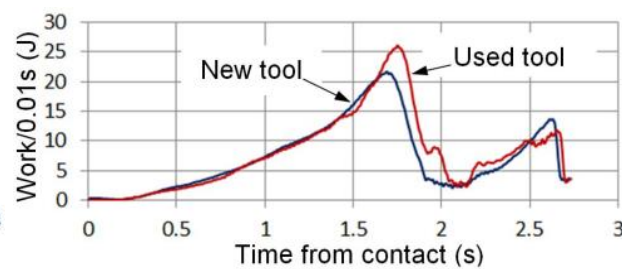

Fig. 19 Energy consumption from torque

Fig. 20 shows the work in a friction drilling cycle concerning the four tested feed rate control strategies. The feed for $F_{\text {Const }}, F_{S e c}$ and $F_{\text {Lin }}$ was determined according to Fig. 6. The feed for $F_{A C}$ strategy was determined as in Fig. 16.

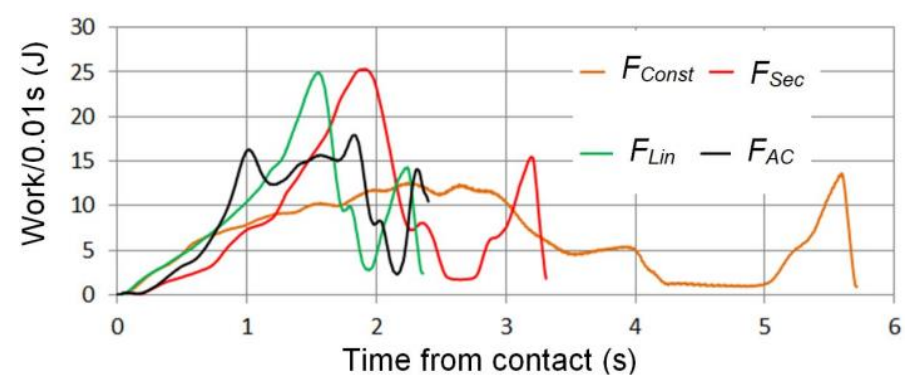

Fig. 20 Energy consumption for various strategies of feed rate control

The maximum energy consumption is in the area where the maximum torque occurs, i.e. at the final section of the hole formation. It should be noted that the maximum energy demand in the drilling cycle with the active function of adaptive control is significantly lower, more than $1 / 4$, as compared to the strategy $F_{S e c}$ and $F_{L i n}$. The conducted research does not confirm the thesis formulated in [25], that "the energy required to drill a hole is independent of the feed rate".

\subsection{Summary}

For the purpose of this work, a sensorless method of adaptive feed control was developed during the friction drilling process. Friction drilling tests have shown that the variable feed rate during friction drilling has no significant effect on the quality of the drilled hole. The surface quality for all four tested strategies is comparable and enables preparation of the correct thread. The length of the flanged bushing ranged from 7.5 to $8 \mathrm{~mm}$. The height of the petals formed at the end of the bushing did not exceed $1 \mathrm{~mm}$. Therefore, the active thread length can be increased more than 3 times. In Fig. 21 comparative characteristics of the four feed rate control strategies tested are presented in a graphic form. 

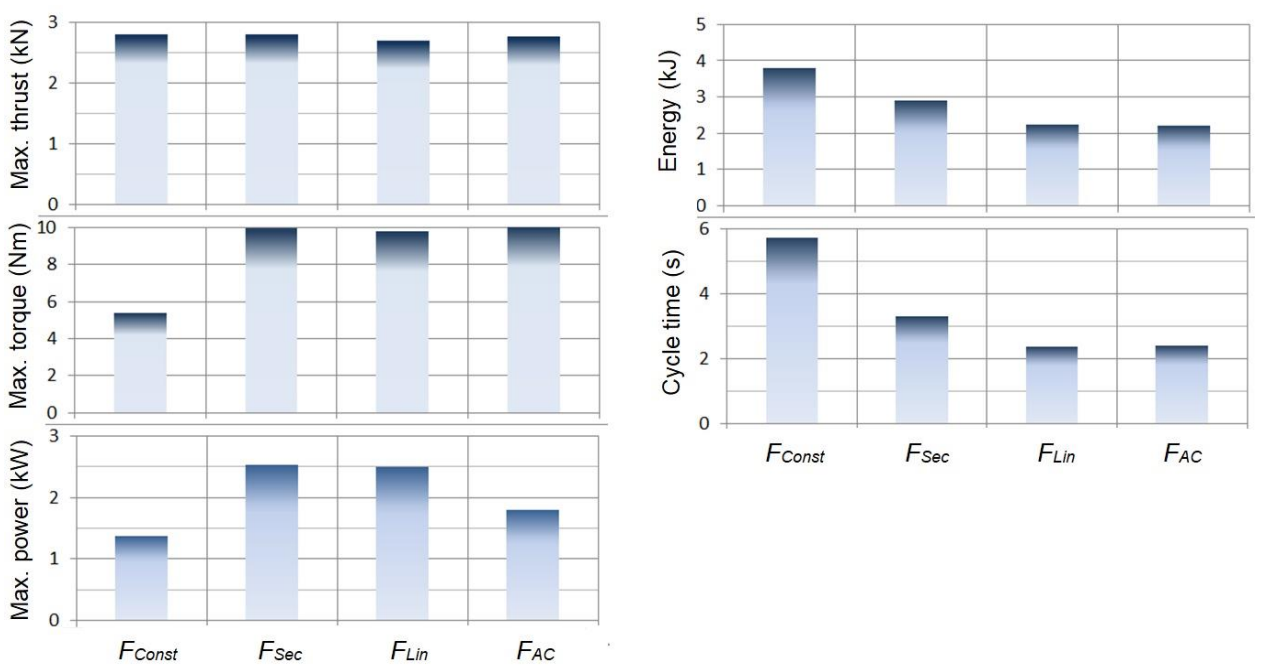

Fig. 21 Output parameters of four tested feed rate control strategies

The maximum thrust for all four tested strategies was at a similar level, which resulted from the assumption made earlier that the tests were comparable. The maximum torque was clearly lower for a constant feed strategy. It remained at a similar level for the other strategies. The maximum power consumed during the cycle was in case of $F_{S e c}$ and $F_{\text {Lin }}$ strategies, while in case of $F_{A C}$ strategy it was clearly lower, likewise for $F_{C o n s t}$, which can be seen in Fig. 2. The energy consumed during the cycle was diverse for particular strategies. Definitely the worst result was obtained for the strategy of constant feed. Also the energy consumed for the $F_{S e c}$ strategy was clearly higher than in case of the $F_{\text {Lin }}$ and the $F_{A C}$ strategies. Particularly poor result was achieved in case of $F_{C o n s t}$ strategy in terms of cycle length due to the long "C" stage (Fig. 4). This was due to the long cylindrical section of the drill used. But even after choosing the optimal length of the cylindrical part of the drill, this strategy in terms of time will achieve the worst results. Cycle times for the $F_{S e c}$ and the $F_{A C}$ strategies are at a very similar level, hence these solutions should be considered equivalent in terms of maximum thrust, maximum torque, energy consumed and cycle time.

The advantage of the $F_{A C}$ strategy over the strategy is, in addition to the lower maximum power used in the $F_{\text {Lin }}$ cycle, also the protection of machine tool drives against excessive overload and the ability to automatically change the feed rate adapted to the current state of the tool. It should be emphasized here that synchronous actions necessary for the implementation of the $F_{A C}$ strategies do not require the use of advanced and expensive numerical control systems. A properly programmed programmable logic controller allows the implementation of intelligent control strategies, also through synchronous actions. 


\section{CONCLUSIONS}

Due to its high complexity and specific features, the friction drilling process requires an unconventional approach to the issues of parametric optimization. The standard approach, consisting in implementation of the experiment plan for process model building, is not applicable here because of the large number of input and output process variables. Therefore, the process models presented so far are fragmentary and for this reason, their practical usefulness is limited. They focus on the selected quality features, ignoring the performance and reliability parameters of the process.

A tool for significant improvement of the performed friction drilling processes has been proposed in the presented paper. A new, intelligent approach to parametric optimization of the friction drilling process, based on the sensorless methods of adaptive control through synchronous actions - of the feed rate set as linearly variable feed, has been developed. The proposed approach is innovative, because it takes into account the criteria that are important for the users, such as cycle time, load of the machine tool drives and tool condition, not being considered in the scientific papers on this issue so far. Thanks to the applied control model, significant improvement of performance, energy and safety indicators of the machine tool and of the tool has been achieved. The practical application of the developed method guarantees a much higher level of process automation and safety.

The authors hope that the presented paper opens a new research area in the field of intelligent control of the friction drilling process. The presented research should be continued in the direction of monitoring of the condition of the drill based on various indicators, such as e.g. energy consumption in the drilling cycle or cycle time.

Acknowledgement: This research did not receive any specific grant from funding agencies in the public, commercial, or not-for-profit sectors.

\section{REFERENCES}

1. Pereira, O., Urbikain, G., Rodriguez, A., Calleja, S., Ayesta, I., López de Lacalle, L.N., 2019, Process performance and life cycle assessment of friction drilling on dual-phase steel, J. Clean. Prod., 213, pp. 1147-1156.

2. Wittke, P., Liu Y., Biermann, D.,Walther, F., 2015, Influence of the production process on the deformation and fatigue performance of friction drilled internal threads in the aluminum alloy 6060, Mater. Test., 57(4), pp. 281288.

3. Urbikain, G., Perez, J.M., López de Lacalle, L.N., Andueza, A., 2016, Combination of friction and form tapping process on dissimilar materials for making nutless joints, J. Eng. Manuf., 236(6), pp. 1007-1020.

4. Chow, H.M., Lee, S.M., Yang, L.D., 2008, Machining characteristic study of friction drilling on AISI 304 stainless steel, J. Mater. Process. Technol., 207, pp. 180-186.

5. Li, H., Wu, J., Chen, L., Zhang, C., Li, Z., 2018, An improved drilling force model in friction drilling AISI 321, J. Phys. Conf. Ser. 1074, doi :10.1088/1742-6596/1074/1/012147

6. El-Bahloul, S.A., El-Shourbagy, H.E., El-Midany, T.T., 2015, Optimization of thermal friction drilling process based on Taguchi method and fuzzy logic technique, Int. J. Sci. Eng. Appl., 4(2), pp. 55-59.

7. El-Bahloul, S.A., El-Shourbagy, H.E., El-Bahloul, A.M., El-Midany, T.T., 2018, Experimental and ThermoMechanical Modeling Optimization of Thermal Friction Drilling for AISI 304 Stainless steel, CIRP J.Manuf. Sci. Technol., 20, pp. 84-92.

8. Demir, Z., Özek, C., Bal M., 2018, An experimental investigation on bushing geometrical properties and density in thermal frictional drilling, Appl. Sci., 8(12), 2658, doi: 10.3390/app8122658

9. Su, K.Y., Welo, T., Wang, J., 2018, Improving friction drilling and joining through controlled material flow, Procedia Manuf., 26, pp. 663-670.

10. Bustillo, A., Urbikain, G., Perez, J.M., Pereira, O.M., López de Lacalle, L.N., 2018, Smart optimization of a frictiondrilling process based on boosting ensembles, J. Manuf. Syst., 48, pp. 108-121. 
11. Pantawane, P.D., Ahuja, B.B., 2011, Experimental investigations and multi-objective optimization of friction drilling process on AISI 1015, Int. J. App. Eng. Res., Dindigul, 2(2), pp. 448-461.

12. Rajesh, J. H. N., Kumar, R., 2017, Process optimization for maximizing bushing length in thermal drilling using integrated ANN-SA approach, J. Braz. Soc. Mech. Sci. Eng., 39(1), pp. 5097-5108.

13. Jiang, Z., Liu, X., Bu, J., 2010, Optimization of thermal friction drilling using grey relational analysis, Adv. Mater. Res., 154-155, pp. 1726-1738.

14. Ku, W.L., Hung, C.L., Lee, S.M., Chow, H.M., 2011, Optimization in thermal friction drilling for SUS 304 stainless steel, Int. J. Adv. Manuf. Technol., 9-12(53), pp. 935-944.

15. Kumar, R., Hynes, N.R.J., 2019, Prediction and optimization of surface roughness in thermal drilling using integrated ANFIS and GA approach, Int. J. Eng. Sci. Technol., 23(1), pp- 30-41.

16. Patil, S.S., Bembrekar, V., 2016, Optimization and thermal analysis of friction drilling on aluminium and mild steel by using tungsten carbide tool, Int. Res. J. Eng. Technol., 3(12), pp. 1468-1474.

17. Dehghan, S., Ismail, M.I.S., Ariffin, M.K.A., Baharudin, B.T.H.T., Sulaiman, S., 2017, Numerical simulation on friction drilling of aluminum alloy, Mater. Werkst., 48(3-4), pp. 241-248.

18. Dehghan, S., Ismail, M.I.S., Ariffin, M.K.A., Baharudin, B.T.H.T., 2019, Measurement and analysis of thrust force and torque in friction drilling of difficult-to-machine materials, Int. J. Adv. Manuf. Technol., 105, pp. 2749-2769.

19. Krasauskas, P., 2011, Experimental and statistical investigation of thermo-mechanical friction drilling process, Mechanika, 17(6), pp. 681-686.

20. Miller, S.F., Blau, P.J., Shih, A.J., 2007, Tool wear in friction drilling, Int. J. Mach. Tools and Manuf., 47(10), pp. 1636-1645.

21. Mutalib, M.Z.A., Ismail, M.I.S., Jalil, N.A.A., As'arry, A., 2018, Characterization of tool wear in friction drilling, J. Tribol., 17, pp. 93-103.

22. Ozler, L., Dogru, N., 2013, An experimental investigation of hole geometry in friction drilling, Mater. Manuf. Process., 28(4), pp. 470-475.

23. Hanumanhta, Rao K., Gopichand, A., Pavan Kumar, N., Jitendra K., 2017, Optimization on machining parameters in friction drilling process, Int. J. Mech. Eng. Technol., 8(4), pp. 242-254.

24. Ambhore, N., Kamble, D., Chinchanikar, S., Wayal, V., 2015, Tool condition monitoring system: A review, Mater. Today: Proc., 2(4-5), pp. 3419-3428.

25. Miller, S.F., 2006, Experimental analysis and numerical modeling of the friction drilling process, Thesis, Univ. of Michigan, $127 \mathrm{p}$. 